BULLETIN Bulletin hispanique

HISPANIQUE Université Michel de Montaigne Bordeaux

$113-2$ | 2011

Varia

\title{
Poesía, historia y mito
}

el tema de la muerte en Antonio Machado y Federico García Lorca

\section{Luis Galván}

\section{(2) OpenEdition}

\section{Journals}

Edición electrónica

URL: http://journals.openedition.org/bulletinhispanique/1460

DOI: 10.4000/bulletinhispanique. 1460

ISSN: $1775-3821$

Editor

Presses universitaires de Bordeaux

\section{Edición impresa}

Fecha de publicación: 1 diciembre 2011

Paginación: 751-775

ISBN: 978-2-86781-793-9

ISSN: 0007-4640

\section{Referencia electrónica}

Luis Galván, «Poesía, historia y mito », Bulletin hispanique [En línea], 113-2 | 2011, Publicado el 01 diciembre 2014, consultado el 19 abril 2019. URL : http://journals.openedition.org/

bulletinhispanique/1460 ; DOI : 10.4000/bulletinhispanique.1460 


\title{
Poesía, historia y mito: el tema de la muerte en Antonio Machado y Federico García Lorca
}

\author{
LuIs GALVÁN \\ GRADUN - Universidad de Navarra - España
}

La poésie d'Antonio Machado tente de répondre à la question de la vie après la mort par les mythes du renouvellement cyclique de la végétation d'abord, puis par le pouvoir de la mémoire et de l'imagination. Federico García Lorca envisage comment la mort configure le destin individuel et caractérise une civilisation. Donnant aux mythes cycliques une importance plus grande que Machado, il peut parler avec force de phénomènes collectifs mais il s'éloigne de la réalité des morts indivuelles.

La poesía de Antonio Machado trata de responder a la cuestión de la vida después de la muerte primero con mitos de renovación cíclica vegetal y después recorriendo al poder de la memoria y la imaginación. Federico García Lorca examina cómo la muerte configura la vida individual y caracteriza toda una civilización; al dar a los mitos cíclicos un papel mayor que Machado, puede hablar con fuerza de fenómenos colectivos pero se distancia de la realidad de las muertes individuales.

Antonio Machado's poetry attempts to answering the question of an afterlife, firstly by means of the myths of cyclical vegetation renewal, then by the power of memory and imagination. Federico Garcia Lorca shows in what ways death configures the individual fate as well as characterizes a civilization. Cyclical myths play a stronger role in Lorca than in Machado, allowing him to speak forcefully about collective issues, but estranging him from the reality of individual deaths.

Mots-clés : Poésie - Mort - Antonio Machado - Federico García Lorca.

Bulletin Hispanique, Tome 113, nº 2 - décembre 2011 - p. 751 à 775. 
Si la muerte es un tema universal y casi consubstancial a la literatura, no $\checkmark$ hay que perder de vista que lo designado como «muerte» puede variar drásticamente según tiempos y lugares, no solo en la forma de presentarse a las conciencias, sino también en su misma realidad biológica: las causas, la edad de morir. En España, la mortalidad comienza a declinar en las primeras décadas del siglo XX, primera fase de la llamada "transición demográfica». De 1900 a 1930, la esperanza media de vida al nacer aumenta de 34,9 hasta 49,9 años. En 1900 sobrevive poco más de la mitad de la población nacida treinta ańos antes; en 1930, sobrevive más del $70 \%$ de ese segmento de edad y más de la mitad de los nacidos sesenta años antes (Dopico y Reher 3136). Las costumbres y mentalidades no se dejan cuantificar de esa manera, pero es indudable que están en marcha los procesos que van a caracterizar las vivencias en torno a la muerte en Occidente en el siglo XX: el disimulo y la represión, la medicalización, en el marco de la racionalización, la secularización y el individualismo (Ariès 553-95; Vovelle 673-761; Elias). Es en esta perspectiva donde hay que poner las representaciones de la muerte por poetas como Antonio Machado y Federico García Lorca. No pueden considerarse tan solo como elementos de un corpus sincrónicamente considerado ni como momentos de un fluir homogéneo de la tradición; son las manifestaciones específicas de una época de cambios demográficos y sociales, y forman parte del entramado de voces de la sociedad: discursos que contrastan con otros discursos, compitiendo por la autoridad de la palabra, por la apropiación verbal de una realidad cambiante y elusiva (ver Bakhtin 275-85).

A la vez, una más detenida atención a la poesía en este marco puede ayudar a la aclaración de algunas cuestiones que la sociología y la historia de las mentalidades han dado por resueltas de forma demasiado simple. Así, Philippe Ariès habla en general del tabú de la muerte, del pudor y la desorientación ante ella (565-66, 572-77). Sin embargo, Michel Vovelle señala irónicamente que de ese tabú se habla mucho (687), y distingue entre el tabú a nivel del inconsciente colectivo, y las abundantes expresiones en la consciencia clara del discurso formalizado, ideológico y literario (726-27). A pesar de esta observación, Vovelle no llega a profundizar en las relaciones entre lo uno y lo otro, sino que las describe desde un punto de vista externo como "discordancia», y sugiere un mero esbozo de explicación psicológica: la literatura como la compensación o el complemento y válvula de escape para el forzoso silencio social $(727,739)$.

En cuanto a Norbert Elias, señala que las personas de épocas anteriores contaban con un discurso formalizado y aceptado en sociedad que les daba seguridad y recursos para enfrentarse a la muerte, mientras que la sociedad 
actual ha perdido tales formalizaciones y deja al individuo abandonado a su propia espontaneidad, lo que resulta en desorientación y mutismo (33-39). El caso es que Elias presenta el discurso formalizado tradicional mediante poesías del siglo XVII (28-32), pero nada dice de la poesía del XX, aunque esta no se ha ocupado menos de la muerte. ¿Qué sucede con ella? ¿Por qué no proporciona un lenguaje para enfrentarse a la muerte? Podría responderse que la poesía contemporánea es elitista y minoritaria y no es capaz de configurar un discurso social. ¿Pero no podría al menos dar un lenguaje y asegurar una actitud al poeta mismo que habla de la muerte en sus versos? Federico García Lorca, en una entrevista de 1934, decía lo siguiente:

No puedo tolerar a los viejos. No es que los odie. Ni que los tema. Es que me inquietan. No puedo hablar con ellos. No sé qué decirles. Sobre todo aquellos viejos que piensan que, por solo serlo, están en todos los secretos de la vida. Eso que llaman experiencia y que tanto nombran los viejos, no la concibo. En una reunión de ancianos, yo no sabría decir una palabra. Me aterrorizan esos ojillos grises, lacrimosos, esos labios en continuo rictus, esas sonrisas paternales, ese afecto tan indeseado como puede serlo una cuerda que tire de nosotros hacia un abismo... Porque eso son los viejos. La cuerda, la ligazón que hay entre la vida joven y el abismo de la muerte. (García Lorca iii: 527)

Ante lo cual el entrevistador comenta: "García Lorca es un muchacho alegre, despreocupado hasta de sí mismo. Pero acaba de nombrar la muerte y su rostro se ha transfigurado» (527). Está claro que entrevistador y entrevistado consideran que la muerte es cosa de viejos y que un joven debe o debería mantenerla lejos de sí, de su cuerpo y de su mente (no está tan claro si Lorca era "un muchacho» en 1934). Esto es síntoma de un cambio de mentalidad: la consigna memento mori se ha desvanecido; pero además tiene un respaldo objetivo en el cambio demográfico. Antes del siglo XIX, el concebir la muerte como cosa de viejos era, simplemente, estar poco informado de la realidad ${ }^{1}$; pero en 1934 empieza a ser estadísticamente justificable.

Ciertamente, el comentario recién citado no es típico de Lorca en lo que tiene de inhumanidad e incoherencia («no es que los tema... me aterrorizan»). Ahora bien, es paradigmático de lo que dice Elias describiendo la situación

1. «No sé con qué vergüença la llamamos muerte súbita, pues cada hora vemos que se entra por todos nuestros sentidos. Desde nuestra niñez, ¿qué otra cosa oýmos sino gemidos de los que se mueren? ¿Qué otra cosa vemos sino mortuorios, enterramientos, lloros, sepolturas y letreros de muertos? [...] ¿quién ay que no aya estado dos dedos de la muerte: o por tempestad, o por ladrones, o por guerra, o por desastre, o por pestilencia, o por enfermedad? Dondequiera que te buelvas está la muerte en celada» (Erasmo 250). 
general en el siglo XX: dificultad para la identificación con enfermos, ancianos y moribundos; consiguiente falta de empatía y de comunicación con ellos; su expulsión prematura del mundo de los vivos, jóvenes y sanos (8-10). En términos más generales, hay un miedo a la nada que desencadena intransigencia y destrucción cuando el ser humano no es capaz de asumir su propia contingencia (Eagleton 2005: 215-28).

En resumen, este trabajo tiene dos objetivos, histórico uno y metodológico el otro. Desde el punto de vista histórico, se trata de contribuir a la comprensión de la poesía en torno a la muerte escrita por Antonio Machado y Federico García Lorca. No se persigue una descripción ni una reinterpretación; existen monografías y estudios de detalle sobre los poemas pertinentes, su encuadre biográfico, su relación con las personales poéticas de sus autores y con la tradición española, cuya validez y relevancia puede asumirse en general ${ }^{2}$. El objetivo es insertar estos poemas en un marco histórico, ideológico y social, para verlos como una búsqueda de lo que el poeta puede decir sobre la muerte aquí y ahora; como unos discursos que se enuncian entre otros, frente a otros. Desde el punto de vista metodológico, se pretende ofrecer a los estudios sobre el tema de la muerte una propuesta de síntesis entre historia y poética, frente a los panoramas de la muerte que engullen la literatura sin tener en cuenta su especificidad (Ariès, Vovelle) y frente a la sistemática sobre la literatura y la muerte elaborada al margen de la historia (Picard). Al cabo, está aún pendiente un desiderátum del Formalismo Ruso, el analizar la correlación de la serie literaria con las demás series sociales (Tynianov y Jakobson 140), que se encuentra ahora con una exigencia del momento actual: la Teoría debe explorar nuevos temas y tabúes, como el de la muerte, para contribuir a un cambio social y a una vida más plena (Eagleton 2005: 227-28).

\section{Antonio Machado}

La muerte aparece de dos maneras en la poesía de Antonio Machado: como asunto más o menos general, y como acontecimientos concretos (la

2. Para Antonio Machado, dan visiones de conjunto Cobos, Alonso, Correa 1977; sobre la muerte en su pensamiento y poética, Cerezo Galán 310-30. Es llamativo que se hable poco de la muerte cuando se tratan las relaciones entre Machado y Heidegger (Sánchez Barbudo 1959: 298-315; Ciplijauskaité). Para García Lorca, ver Correa 1975, López Castellón ; Urrea ; sobre la muerte en su poética, ver Egginton, Poust, Nandorfy, Reinholtz. Sobre la tradición del tema en la literatura y cultura española, ver Salinas, Fernández Alonso. Me referiré a otros trabajos más específicos en el curso de la argumentación. 
muerte de este o de aquel; la muerte de Leonor, sobre todo) que demandan una toma de postura. En Soledades, Galerías y Otros poemas predomina la primera forma, con orientaciones muy variadas y una presencia ciertamente notable «en el primero, segundo o tercer plano o en el fondo o trasfondo del cuadro» (Cobos 51). Por ejemplo, se aborda «la muerte de un amigo» (IV) con un tono de objetividad e ironía («Tierra le dieron una tarde horrible»; "Un golpe de ataúd en tierra es algo / perfectamente serio»); o bien la expectativa y la angustia ante la muerte propia (XXI, XXXV, LVI, LXXV); bien las imaginaciones y dudas sobre una existencia después de la muerte (LXX, LXXVIII); etcétera.

Campos de Castilla se abre con una contemplación de la muerte propia en "Retrato» (XCVII); pero en el desarrollo del tema hay que distinguir entre la primera edición de 1912 y la ampliación del libro a partir de las Poesías completas de 1917. En 1912, las referencias directas a la muerte están relacionadas con lo que se ha llamado el "tema de España» (Correa 1977: 141-42): asesinatos, ejecuciones como en «Un criminal» (CVIII) y «La tierra de Alvargonzález» (CXIV). En esta línea se insertará más tarde la necrología irónica del inmoral e inútil «caballero andaluz»: «Llanto de las virtudes y coplas por la muerte de don Guido» (CXXXIII).

Como es sabido, poco después de aparecer aquella edición sobreviene una muerte real y cercana, la de Leonor. Machado sufre una crisis de la que dan testimonio dos cartas, bien conocidas pero que es preciso citar aquí. A Juan Ramón Jiménez le escribe sucintamente: "Cuando perdí a mi mujer pensé pegarme un tiro» (iii: 1519). Al año siguiente, expone a Unamuno reflexiones algo más amplias:

La muerte de mi mujer dejó mi espíritu desgarrado. Mi mujer era una criatura angelical segada por la muerte cruelmente. Yo tenía adoración por ella; pero sobre el amor está la piedad. Yo hubiera preferido mil veces morirme a verla morir, hubiera dado mil vidas por la suya. No creo que haya nada extraordinario en este sentimiento mío. Algo inmortal hay en nosotros que quisiera morir con lo que muere. Tal vez por esto viniera Dios al mundo. Pensando en esto, me consuelo algo. Tengo a veces esperanza. Una fe negativa es también absurda. Sin embargo, el golpe fue terrible y no creo haberme repuesto. Mientras luché a su lado contra lo irremediable me sostenía mi conciencia de sufrir mucho más que ella, pues ella, al fin, no pensó nunca en morirse y su enfermedad no era dolorosa. En fin, hoy vive en mí más que nunca y algunas veces creo firmemente que la he de recobrar. Paciencia y humildad. (iii: 1537) 
La desorientación se muestra en las contradicciones: «algo inmortal... que quisiera morir»; cree "firmemente» pero solo «algunas veces». Hay, además, una serie de síntomas de la mentalidad moderna ante la muerte: la esperanza de un reencuentro con la amada muerta no está enteramente articulada con una fe religiosa (Ariès 464-67; Vovelle 532-33, 588); siendo «irremediable» la muerte, es preferible ocultar el pronóstico al enfermo (Ariès 553-57); la tuberculosis, al menos, es una enfermedad limpia, que permite la idealización del enfermo y no trastorna gravemente la convivencia (Ariès 561-63; Sontag).

Esa misma desorientación se canaliza en una serie de poemas que Machado compuso en los años siguientes e incorporó a Campos de Castilla en 1917 (Terry 53-62; Ribbans). Son especialmente reveladores los textos centrales de este grupo, donde la posición y las ideas del hablante fluctúan sin cesar. Sus interlocutores son Dios (CXIX), su corazón (CXX), Leonor (CXXI, CXXII), la muerte (CXXIII); lo que ha hecho morir a Leonor ha sido bien la voluntad de Dios (CXIX), bien la muerte personificada, con sus «dedos muy finos» (CXXIII); la esperanza se basa en una vaga fe: «No todo / se lo ha tragado la tierra» (CXX) o bien en la mera incertidumbre: "iquién sabe / lo que se traga la tierra!» (CXXII). El poema CXXI parece incluso una alucinación.

Si el sentido biográfico de estos poemas está claro, su sentido histórico resalta mejor cuando se contrasta con textos del otro poeta castellano en quien resulta tópico pensar en conexión con la muerte de la mujer amada. Garcilaso de la Vega tenía recursos ideales y verbales para hablar de la muerte con otro aplomo. Cuando ordena su testamento en 1529 se expresa de la siguiente manera:

Por cuanto [...] la muerte es natural a los hombres, y es cosa cierta, y la hora e día en que ha de ser incierta, e de las buenas obras que hubiéremos hecho daremos cuenta en el día temeroso del juicio [...], ordeno este mi testamento en la forma e manera siguiente: Primeramente encomiendo mi ánima a Dios nuestro Señor para que a él le plega e sea servido cuando fuere su voluntad de llevar mi ánima a la su gloria donde los fieles cristianos deseamos ir y estar. (275-76)

Aquí se trata de una creencia y una práctica que cuentan con pleno respaldo social, y que se expresan con unas fórmulas enteramente convencionales. En 1535, las mismas ideas se destinan a consolar al Duque de Alba por la muerte de su hermano don Bernaldino de Toledo, diciendo que éste

subió por la difícil y alta vía, de la carne mortal purgado y puro, 
en la dulce región del alegría, do con discurso libre ya y seguro mira la vanidad de los mortales, ciegos, errados en el aire escuro, y viendo y contemplando nuestros males alégrase d'haber alzado el vuelo

a gozar de las horas inmortales. (elegía I, vv. 259-67)

Aquí el carácter compartido y público de la creencia asegura la comunicación entre el poeta y su destinatario. Por último, la pura expresión a solas se apoya en la misma base, en un caso de ficción que la leyenda erudita ha querido identificar con un episodio real de la vida del poeta (Iglesias Feijoo). Nemoroso se dirige en estos términos a Elisa:

Divina Elisa, pues agora el cielo con inmortales pies pisas y mides, y su mudanza ves, estando queda, ¿por qué de mí te olvidas y no pides que se apresure el tiempo en que este velo rompa del cuerpo y verme libre pueda, y en la tercera rueda, contigo mano a mano, busquemos otro llano, busquemos otros montes y otros ríos, otros valles floridos y sombríos donde descanse y siempre pueda verte ante los ojos míos, sin miedo y sobresalto de perderte? (égloga I, vv. 394-407)

Garcilaso afronta la muerte propia o ajena, e imagina la de la mujer amada, en una situación y con un lenguaje bien definidos. No tiene que buscar los fundamentos de su actitud, no incurre en contradicciones. Naturalmente, esa matriz puede generar discursos muy diferentes, desde las fórmulas estereotipadas del testamento hasta la voz personal y creativa de la égloga primera. Esto - palabras, que no ideas nuevas- es lo que se esperaba del poeta, según comentario de Herrera: «sin duda alguna es muy difícil decir nueva y ornadamente las cosas comunes, y así la mayor fuerza de la elocución consiste en hacer nuevo lo que no es», "sin procurar los sentimientos remotos del común juicio de los hombres» $(560,564)$.

La diferencia de situación histórica con Machado resulta más patente si se compara la última estrofa citada con un poema de Campos de Castilla (CXXII): 


\begin{abstract}
Soñé que tú me llevabas por una blanca vereda, en medio del campo verde, hacia el azul de las sierras, hacia los montes azules, una mañana serena. [...] ¡Eran tu voz y tu mano, en sueños, tan verdaderas!... Vive, esperanza, ¡quién sabe lo que se traga la tierra!
\end{abstract}

La misma situación: un reencuentro con la amada muerta, en una naturaleza idílica; pero el marco lo cambia todo. Nemoroso da por cierto que ese reencuentro tendrá lugar, en el más allá, en una nueva vida inextinguible; tan solo está en cuestión el adelantarlo o posponerlo. En cambio, Machado lo encierra en la ficción de un sueño que la consciencia vigilante no puede apoyar en más que un agnosticismo esperanzado. Esta diferencia se podría tratar analíticamente como un "desplazamiento» desde el modo mítico, que admite lo sobrenatural y la realización plena de los deseos, al modo mimético que exige verosimilitud (Frye 136-40), o como un caso de «restricción de la ley de máximos semánticos», que permite la inserción de un elemento no verosímil en un "mundo articulatorio» verdadero o verosímil (Albaladejo 53-63). Sucede empero que tales análisis presuponen un mismo concepto de realidad, verdad y experiencia posible para ambos poemas; y esto es precisamente lo que puede impedir que se perciba su lógica histórica. El reencuentro en el más allá es cosa que se da por supuesto con absoluta certeza en el sistema de creencias de Garcilaso y sus lectores; es pues, real para ellos en el sentido de que les resuelve problemas; mientras que ello mismo se ha vuelto problemático en una situación como la de Machado, cuatro siglos más tarde, en una Modernidad racionalista y secularizada.

Si la vida en el más allá no es respuesta, sino pregunta para Machado, ¿Cómo la responde? En la carta a Unamuno hay referencias a una religiosidad cristiana. En la poesía prueba otro camino. Se trata de tres poemas muy conocidos; no hará falta más que alinearlos en la perspectiva de esta cuestión. El punto de partida es "A un olmo seco» (CXV):

Al olmo viejo, hendido por el rayo

y en su mitad podrido,

con las lluvias de abril y el sol de mayo

algunas hojas verdes le han salido. [...] 
POESÍA, HISTORIA Y MITO: EL TEMA DE LA MUERTE

Mi corazón espera

también, hacia la luz y hacia la vida,

otro milagro de la primavera.

Se refiere a la primavera de 1912; por tanto, precede a la muerte de Leonor, que tuvo lugar en agosto. Así pues, lo que cabe esperar en el contexto de la renovación primaveral de la naturaleza es una restauración de la vida en el dominio intramundano (Sánchez Barbudo 1969: 244-46): las hojas han brotado «antes que» el olmo sufra la destrucción por el hierro, el fuego o el viento y el mar (vv. 15-25). La orientación intramundana se confirma en los versos que consideran las posibilidades de perduración en forma transfigurada ("[antes que...] el carpintero / te convierta en melena de campana, / lanza de carro o yugo de carreta», vv. 16-18), lo que envuelve en incertidumbre la existencia más allá de la muerte.

El motivo de la renovación natural aparece en un poema (CXXIV) a propósito de otra primavera posterior:

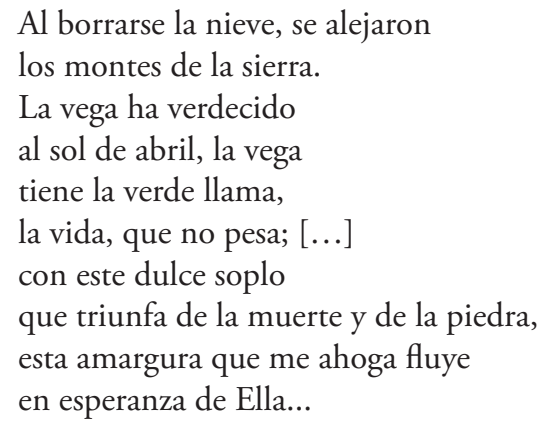

Como la nieve, la amargura se funde y fluye en una corriente de esperanza. Ya no puede ser una esperanza intramundana como la del poema CXV, sino que se trata de lo que escribía a Unamuno: «algunas veces creo firmemente que la he de recobrar». Si en la carta esbozó una fundamentación religiosa, aquí en cambio prueba a insertar su esperanza en una experiencia del ciclo natural: como la primavera sigue al invierno, cabe esperar que una nueva vida siga a la muerte.

Este planteamiento tiene una trayectoria muy corta: se liquida en el poema CXXVI, "A José María Palacio», uno de los textos más comentados de Campos de Castilla. Hay general acuerdo en que este poema distingue claramente entre el ciclo natural de renovación tras el invierno y la irreversibilidad del destino humano que la muerte sella (Correa 1977: 139; Güntert 65-66). Lo significativo es que hace comparecer el posible motivo para esperar, ya 
utilizado en este sentido en poemas anteriores, y sin embargo ahora renuncia a fundamentar la esperanza, e incluso a expresarla ${ }^{3}$. Hay, al contrario, un retorno a la pura facticidad, enunciada escuetamente: el «Espino donde está su tierra» (v. 32), como en el poema de Soledades "En el entierro de un amigo» (IV): «Tierra le dieron». Responde a la lógica que «A José María Palacio» vaya seguido inmediatamente por dos poemas (CXXVII, CXXVIII) que hablan de ruptura, alejamiento, soledad y nueva situación en Baeza, con un ritmo mucho más rápido.

Sin embargo, Machado aún va a sacar las consecuencias de la actitud que representa "A José María Palacio» en un nivel colectivo, universal humano, y con lenguaje mítico. Lo hace en el texto que abre Nuevas canciones: "Olivo del camino» (CLIII), una versión del mito de Démeter que proyecta, como escribe Correa, «las fuerzas de la renovación al ritmo de la resurrección anual de la naturaleza, pero también a la raza de los mortales» (1977: 144). Hay que notar la diferencia entre esas proyecciones. El poema es significativo por lo que dice y por lo que calla: se detiene en el episodio de Demofón, y omite el núcleo del relato mítico, la recuperación de Perséfone. Ahora bien, Perséfone es un caso de retorno del mundo de los muertos, mientras que Demofón alcanza solamente una robustez física que no incluye la inmortalidad:

-Tal es, raza mortal, tu cobardía.

Mi llama el fuego de los dioses era. [...]..

Vuelve al halda materna, y tu nodriza

no olvides, Demofón, que fue una diosa;

ella trocó en maciza

tu floja carne y la tiñó de rosa,

$\mathrm{y}$ te dio el ancho torso, el brazo fuerte,

y más te quiso dar y más te diera:

con la llama que libra de la muerte,

la eterna juventud por compañera. (vv. 71-85)

Así pues, el individuo humano habrá de morir, a diferencia de la naturaleza que se renueva en flor y fruto con cada ciclo de las estaciones (vv. 86-112).

Abandonado el proyecto de fundamentación mítica de una existencia después de la muerte, Machado desarrollará dos tendencias en el tratamiento de este tema. Para personajes de ficción como Abel Martín, presentará la muerte como elemento inmanente de la vida y como disolución en la nada; la representación del más allá, en estos casos, es una especie de sueño

3. Guillén analiza la «estilística del silencio» de este poema, la eficacia comunicativa de lo no dicho. 
(Cobos 123-41; Cerezo 319-30; Alonso). En cambio, para personas reales sí imagina una especie de nueva existencia después de la muerte. Es más explícito en el recuerdo de Giner de los Ríos (CXXXIX): «¿Murió?... Sólo sabemos / que se nos fue por una senda clara, [...] / Y hacia otra luz más pura / partió el hermano de la luz del alba»; más escueto en el de García Lorca (LXXXIV S): «Se le vio caminar solo con ella [...] / Hoy como ayer, gitana, muerte mía, / qué bien contigo a solas»; únicamente en el caso de Rubén Darío (CXLVIII) recurre a la imagen del retorno vegetal: «¿donde fuiste, Darío, la armonía a buscar? [...] / ¿te ha llevado Dionysos de su mano al infierno / y con las nuevas rosas triunfante volverás?».

Es distinto el planteamiento en las dos poesías -quizá borrador y versión definitiva- donde Machado se dirige a su padre, veinte y más años después que este muriese. En el más antiguo (XXXI S, de 1916) hay un trabajo de la memoria:

Ya casi tengo un retrato

de mi buen padre, en el tiempo,

pero el tiempo se lo va llevando. [...]

Pasea -oh padre mío ¡todavía!

estás ahí, el tiempo no te ha borrado.

Ya soy más viejo que eras tú, padre mío, cuando me besabas.

Pero en el recuerdo, soy también el niño que tú llevabas de la mano.

¡Muchos ańos pasaron sin que yo te recordara, padre mío!

¿Dónde estabas tú esos años?

¿Dónde estaba? ¿Estaba en algún lugar, con una existencia real más allá de la muerte? ¿O la única existencia posible está en el recuerdo de los vivos, y el padre no la tuvo hasta ahora, y la volverá a perder, porque «el tiempo se lo va llevando»? La ambigüedad es más sutil en el soneto incluido en Nuevas canciones (CLXV.iv). Imagina a su padre, «aún joven»; sus ojos vagan y «ya escapan de su ayer a su mañana; / ya miran en el tiempo ¡padre mío! / piadosamente mi cabeza cana». Suele interpretarse -y es natural- que el poema trae al padre muerto al «ahora», al «presente» de la enunciación, sea por la imaginación del hijo (Sánchez Barbudo 1969: 339-40), sea de forma más o menos misteriosa (Alvar 50-51), aunque ciertamente también puede leerse a la inversa, como si el padre imaginase a su hijo envejecido, como si el hablante fuese trasladado al «entonces» enunciado en el poema. En cualquier caso, pero sobre todo en el primero, más conforme con el borrador de 1916, hay una nueva fundamentación para la existencia después de la muerte y para la posibilidad de reencontrarse con los muertos; no, como en 
los poemas de Leonor, por las fuerzas de renovación de la naturaleza, sino por el poder de la memoria y la imaginación humana.

En resumen, Antonio Machado se ocupa continuamente de la muerte y de la existencia después de ella, "muerte y trasmuerte», como lo formuló Dámaso Alonso. Es sobre todo el discurso sobre la «trasmuerte» el que se incardina en el mundo real, porque responde a cuestiones que le plantean a Machado los fallecimientos de personas reales: su padre, Leonor, Giner, Darío, García Lorca. Ese discurso puede, por tanto, ubicarse en el entramado social. Se ha visto que Machado no puede dar por cierta la existencia después de la muerte; la esperanza necesita elaborar una justificación. La postura religiosa queda excluida de la poesía - aunque le da cabida en la carta a Unamuno-. Ensaya una fundamentación mítica, pero enseguida renuncia a ella. Esta posición es significativa en un contexto donde los mitos cíclicos de renovación vegetal y renacimiento humano están en boga: se encuentran desde La rama dorada (1890) de Sir George Frazer hasta el ensayo de Mikhail Bakhtin sobre el cronotopo en la novela ([1937-1938] 206-24), pasando por La decadencia de Occidente (1918-1922) de Oswald Spengler y La tierra baldia (1922) de T. S. Eliot, sin olvidar el prólogo del propio Antonio Machado a la reedición de Soledades en $1919^{4}$. Con dicha renuncia, Machado mantuvo el cuestionamiento sobre la muerte y el más allá en el nivel del individuo, mientras que el mito tendía a darle un enfoque colectivo y a generar mentalidades apocalípticas, escatológicas, en lo artístico como en lo político y social (Kermode 93-124; Eagleton 1990: 316-23; Griffin 1-12). Quedando al margen de toda tendencia, religiosa o mítica pagana, versos como «se nos fue por una senda clara, [...] hacia otra luz más pura», de la elegía a Giner, parecen un mero tópico arrastrado al vacío, como una hoja seca; en cambio, el trabajo de la memoria y la imaginación en los poemas a su padre logra poner un cierto fundamento, aunque de tono menor y sin reclamar validez universal.

\section{Federico García Lorca}

La poesía de Federico García Lorca arranca de otro nivel histórico e ideológico que la de Machado. Como se expuso al principio, en 1900 solamente sobrevivía la mitad del censo de treinta años; en cambio, cuando Lorca cumple esa edad, sobrevive más del $70 \%$ de sus compañeros de generación, y más de la mitad de los nacidos sesenta años antes; y los niños

4. La relación de dicho prólogo con «Olivo del camino» ha sido señalada por Macrí (Machado i: 190-91) y Sánchez Barbudo (1969: 370). 
nacen con una esperanza media de vida de casi cincuenta años (Dopico y Reher 31-36). La citada entrevista a Lorca de 1934 deja constancia de que la muerte se considera cosa de viejos. Hay más indicios de cómo progresa su ocultamiento, precisamente porque Lorca la busca continuamente. En un temprano escrito inédito de carácter autobiográfico, cuenta cómo murió en Fuente Vaqueros el anciano "compadre Pastor» cuando él era un niño (García Lorca, iv: 851-53 ; ver Gibson 55-58):

Yo estuve a visitarle porque preguntaba por mí... Estaba como muerto, con la boca entreabierta y los ojos cerrados [...]. Mi madre me tomó en brazos y me sentó en la cama. Él se incorporó, ayudado de una sobrina, y pasándome sus manos por mi cara me estuvo acariciando un rato. [...] Mi madre me sacó fuera del cuarto y me dijo que me fuera.

Más tarde, escucha los comentarios de las criadas: «una de ellas afirmaba que de las dos de la mañana no pasaba y añadían: "le han tenido que quitar de la vista el cuadro que representa el purgatorio porque lo mira de una manera que da miedo..."». Muere antes del amanecer; todo el día lo velan y por la tarde lo llevan a enterrar.

La comitiva se paró y todos cercaron el féretro y lo destaparon y el señor cura lo roció de agua bendita... Mi pobre compadre pastor estaba rígido y con las manos cruzadas. Un pañuelo de seda le cubría piadoso la cara. Uno de sus amigos se lo quitó, pero yo no pude verle el rostro porque mi padre me tapó los ojos con sus manos.

Esta muerte tiene un carácter público y ritual; sin embargo, comienzan los elementos de pudor: se abrevia el contacto del niño con el moribundo y se le impide la visión del cadáver. Parece que al propio moribundo le quieren evitar una impresión demasiado fuerte, escamoteándole un cuadro.

En la Residencia de Estudiantes, Lorca hace representaciones mímicas de su muerte: agonía, descomposición, conducción y entierro (Gibson 407). Que esto se perciba como una peculiaridad notable, y que llene de «tensión» y "angustia» a sus amigos, como dice Dalí, revela que en alguna medida se ha formado ya un tabú que Lorca estaba rompiendo. Las respuestas que generan tanto su morir de mentiras como su poesía acerca de la muerte han de tenerse presentes para relativizar lo que dice el propio Lorca en la conferencia Juego y teoría del duende acerca de la ubicuidad y publicidad de la muerte en España. En cuanto a la existencia después de la muerte, concibiéndola en el marco de la escatología católica, Lorca la liquida en sus 
primeros libros, al hilo de unos sepulcros en Impresiones y paisajes (1918) y entre las dudas e ironías de Libro de poemas (1921) 5 .

En adelante, planteará la muerte casi exclusivamente como elemento intramundano, como fuerza misteriosa y destino que arrastra y consuma las vidas. Así aparece ya en Poema del cante jondo (escrito a partir de 1921 y publicado en 1931), y adquiere una forma más concreta en Romancero gitano (1928), con la combinación de lo mítico y lo realista que él mismo destacó (iii: 181). Hay que examinar qué tiene de mito la muerte, y la muerte de determinados personajes, con una configuración verbal muy particular.

Lorca dice que «la luna como bailarina mortal» del primer romance es un mito inventado; inventado por él, se entiende. Bien puede ser, pero el enfrentarla con un niño, la fascinante atracción que este siente por sus encantos (Fernández Alonso 289; Correa 1975: 41), y el presentar la muerte con el eufemismo de «los ojos cerrados» (vv. 16, 24), conecta este poema con el mito de Endimión, el pastor que quedó para siempre dormido con su eterna juventud por amor de la Luna. Esta conexión proporciona una clave que configura Romancero gitano: sus personajes mueren en plena juventud; por tanto, escapan al proceso natural de envejecimiento y degeneración que tanto chocaba a Lorca y que se iba generalizando en aquellos años con el aumento de la esperanza de vida. El hecho adicional de que muchas de las muertes del libro sean violentas se ha interpretado como un resultado del choque entre pasión y orden (Fernández Alonso 301-03); pero esto no vale para los casos de pasión contra pasión, como las reyertas de los romances 3 y 12 , ni para lo ambiguo o misterioso de los romances 4,13 y 14 . Hay que decir, de forma más general, que la muerte detiene la vida en el esplendor de una pasión.

Otro aspecto de lo mítico en Romancero gitano es que «el hombre [...] entra a formar parte de la cadena solidaria e ininterrumpida de la naturaleza cósmica», según expone Correa (1975: 75). Una manera que se ha propuesto de concebir esta participación es el ingreso en los ciclos de renovación astronómica y estacional ${ }^{6}$. Es una configuración mítica que ya se ha visto en la poesía de Antonio Machado; en el Romancero gitano se podrían examinar

5. Quizá lo más conocido de Libro de poemas en este sentido es «Las andanzas de un caracol aventurero», muy irónico respecto del más allá, pero hay otras actitudes representadas en el libro. Sobre la problemática religiosa juvenil de Lorca, ver Gibson 167-71, 197-228; Herrero 1989.

6. Ver Feal 210-13, sobre el Camborio; Herrero 1992, sobre santa Olalla. Loughran (13564) señala que la anécdota de varios romances puede interpretarse no solo como paralelismo, sino como alegoría de fenómenos astronómicos como el curso solar diurno y anual. 
en este contexto algunas alusiones a mitos clásicos como el de Adonis ${ }^{7}$. Sin embargo, el movimiento más generalizado en el poemario no es el ciclo, sino un itinerario regresivo donde se integran el dinamismo, las metáforas y las transformaciones señaladas por Correa (1975: 79-81): se asocian a los personajes sucesivamente clasemas de lo animal, lo vegetal, y lo metálico, mineral, inanimado, para terminar en la categoría de figuras míticas rodeadas de un rito. Por decirlo así, no saltan hacia arriba, de lo humano a lo mítico, sino que se hunden en la escala del ser hasta aparecer en el extremo opuesto.

Las formulaciones más completas de esta regresión se dan en la segunda mitad del poemario. Antońito el Camborio es una figura animal, asociada a los toros, el jabalí y el delfín, hasta que lo hieren y dice: "Ya mi talle se ha quebrado / como caña de maíz» ( $n^{\circ} 12$, vv. 39-40). La muerte lo convierte en figura con el clasema metálico: «Viva moneda que nunca / se volverá a repetir» (vv. 43-44), y acto seguido comienza un rito: «Un ángel marchoso pone / su cabeza en un cojín. / Otros de rubor cansado / encendieron un candil» (vv. 45-48). El Emplazado también comienza asociado a un animal: "Ojos chicos de mi cuerpo / y grandes de mi caballo, [...] / el insomnio del jinete / y el insomnio del caballo" ( $\mathrm{n}^{\circ}$ 14, vv. 2-3, 20-21); le comunican el emplazamiento diciéndole: "Ya puedes cortar, si gustas, / las adelfas de tu patio. [...] porque cicutas y ortigas / nacerán en tu costado, / y agujas de cal mojada / te morderán los zapatos [...] y gusta los aires fríos / de metales y peñascos» (vv. 24-39). Después de muerto, la gente viene a ver su cadáver amortajado (vv. 50-57). Santa Olalla empieza con menciones de un caballo y un toro (n. ${ }^{\circ} 16$, vv. 2, 19); ella aparece como "Flora» (v. 23), sus venas son verdes (v. 27) y su sangre forma «arbolillos» (v. 39). Una vez muerta «su desnudo de carbón / tizna los aires helados» (vv. 53-54) hasta que la cubre la nieve, que no solo tiene el clasema 'inanimado' sino que se representa como un metal: «escuadras de níquel juntan / los picos en su costado» (vv. 65-66). Termina con una imagen celestial: «Olalla blanca en lo blanco. / Ángeles y serafines / dicen: Santo, santo, santo» (vv. 72-74). Es llamativo que ni siquiera en este romance hagiográfico aparezca claramente el motivo de una existencia después de la muerte.

Aunque en algunos casos faltan elementos de la cadena, el sentido general de la marcha es constante a través de romances muy distintos ${ }^{8}$. En «Reyerta»,

7. En el romance «Reyerta» se mencionan «muslos heridos» $\mathrm{y}$ «dos viejas mujeres» (vv. 3334, 10). Como se sabe, Adonis murió de una herida en el muslo, y repartía su vida entre Afrodita y Perséfone, dos mujeres tan viejas como lo son el amor y la muerte.

8. La isotopía del recorrido animal-vegetal-mineral-figura muerta también funciona como matriz de la parodia que es la "Burla de don Pedro a caballo", que comienza "montado en un ágil / caballo sin freno» ( ${ }^{\circ} 17$, vv. 5-6); llega a «una ciudad lejana / entre un bosque 
los personajes van a caballo y luchan con navajas como peces; Juan Antonio el de Montilla tiene «su cuerpo lleno de lirios / y una granada en las sienes» ( ${ }^{\circ} 3$, vv. 19-20), e inmediatamente «monta cruz de fuego / carretera de la muerte» (vv. 21-22), y la última visión es el vuelo de los ángeles (vv. 35-38). En el ya mencionado «Romance de la luna, luna», el niño está ya en el nivel de lo metálico, en la fragua, sobre el yunque, y de allí pasa a una especie de catasterismo: "por el cielo va la luna / con un nińo de la mano» ( $\mathrm{n}^{\circ} 1$, vv. $31-$ 32); lo animal y vegetal son la oportunidad perdida: el caballo, el olivar de los gitanos. También en el «Romance sonámbulo» la gitana es metálica desde el principio, con sus «ojos de fría plata» $\left(\mathrm{n}^{\circ} 4\right.$, v. 8), mientras que él quiere dejar su caballo (v. 26) y lleva las "trescientas rosas morenas» (v. 41) de las heridas. Al final, ella forma una figura prodigiosa, sostenida por la luna sobre el agua.

¿Cuál es el sentido histórico de estos poemas en tanto que discurso sobre la muerte? Lo primero que se puede constatar en un contraste con la poesía de Antonio Machado es el desplazamiento de la problemática. García Lorca no se pregunta por la inmortalidad, sino por la impasibilidad e inmutabilidad. Lo angustioso no es morir ni ser aniquilado, sino vivir, cambiar, decaer. La muerte es precisamente la solución, lo que sustrae a los personajes de ese destino y, en cierta manera, los perfecciona, convirtiéndolos en objeto de atención para ángeles y hombres.

Lo segundo es su orientación hacia lo marginal. García Lorca afirmó en su Juego y teoría del duende que España es un "país abierto a la muerte» (iii: 156), y críticos de la importancia de Pedro Salinas (394) e Ian Gibson (56-57) han señalado que la poesía de Lorca está enraizada en este aspecto de la cultura española. Ahora bien, hay que observar que los ejemplos que da en Juego y teoría son de varios siglos atrás (Quevedo, Valdés Leal) o de marginados contemporáneos como el «reciente mozo de Salamanca, muerto por el toro» (157). En cambio, en un entorno urbano, ilustrado y burgués como la Residencia de Estudiantes, la muerte era un tema peculiar de Federico y chocante para sus amigos. Hay que sospechar que la conferencia tiene algo de recreación, de búsqueda erudita del exotismo, y de mitopoesis; responde al mismo movimiento que el Poema del cante jondo y el Romancero gitano (ver Poust) ${ }^{9}$. García Lorca va a buscar la muerte mítica entre los gitanos, e

de cedros» (vv. 26-27), "pasa por arcos rotos» (v. 32), y termina en el agua «jugando con las ranas» (v. 69), inversión de los ángeles corrientes en el Romancero gitano. Un recorrido inverso, en forma microtextual, se da al comienzo de «Thamar y Amnón»: «La luna gira en el cielo / sobre las tierras sin agua [clasema "mineral"] / mientras el verano siembra [clasema "vegetal"] / rumores de tigre [clasema "animal"] y llama» (nº 18, vv. 1-4).

9. Por eso, es cuestionable la metodología de poner la conferencia Juego y teoría del duende 
imagina allí cómo la pasión, la violencia o un destino misterioso matan a los jóvenes. Una consecuencia de ello es que se enajena precisamente de las circunstancias de su entorno, de la pacificación interna de la sociedad y de la creciente esperanza de vida que configuran, como expone Elias (59-66), la mentalidad actual en torno a la muerte.

En los poemarios posteriores de Lorca se encuentran novedades, aunque es difícil aquilatarlos en su totalidad y en su carácter de discursos acerca de la muerte. Se sabe que anunció títulos como Introducción a la muerte y Poemas a los muertos, que corresponden aproximadamente a Poeta en Nueva York y Divan del Tamarit; con la dificultad adicional de que estos volúmenes aparecieron póstumamente (ver Anderson ; Dennis). En cualquier caso, hay que señalar algunas tendencias, empezando por los anticipos de Poeta en Nueva York que aparecieron en Revista de Occidente en 1931 y en la antología Poesía española de Gerardo Diego al año siguiente.

El primer poema de 1931 lleva por título «Muerte». Una serie de transformaciones de seres vivos, encerrados en un proceso cíclico lleno de «esfuerzo» (v. 1) que engendra dolor («flecha», «alaridos», "puñales»), contrasta con «el arco de yeso, / ¡qué grande, qué invisible, qué diminuto! / sin esfuerzo" (vv. 20-22). Se trata de la liberación de una vida experimentada como angustia, la misma idea del Romancero gitano, incluso con el mismo recorrido de isotopías: una variedad de animales, la «rosa» vegetal, y varios seres inanimados («azúcar», "puñales») hasta el «arco de yeso» (ver Craige 85 ; Nandorfy 209-12) ${ }^{10}$. Esta línea lleva a la serenidad y la búsqueda de la muerte propia en Diván del Tamarit (Anderson 67-76, 80-87; Reinholtz 146-48).

La nueva orientación está representada especialmente en «New-York: oficina y denuncia», donde Lorca enfoca el papel de la muerte en la civilización contemporánea, una civilización de masas burocrática y tecnificada que se alimenta de la sangre de innumerables víctimas, una civilización donde la vida cotidiana en la calle y la tienda de frutas no se distinguen fácilmente de la muerte y el infierno (vv. 54-55). Esta visión genera poemas apocalípticos, como "Ciudad sin sueño", publicado en Poesía española de 1932, y otros que figuran en el volumen («El rey de Harlem», «Danza de la muerte», «Paisaje de la multitud que vomita»). Es significativa la orientación que da García Lorca al motivo de la danza de la muerte: en su origen medieval, era un

como fundamento para una exégesis de los poemas de Lorca; son dos formas de creatividad distintas que habrían de explicarse por una raíz común.

10. Harris (41) analiza el poema en términos semejantes, aunque le da una interpretación global diferente: «Life struggles desperately to avoid death, but death's domination of life is effortless». 
memento mori para todo individuo, de cualquier posición política y social que fuese, mientras que aquí se trata de un final del mundo, o por lo menos de la civilización representada por New York, que la muerte, en su danzar, $\operatorname{arrasa}^{11}$.

Un segundo aspecto de «New-York: oficina y denuncia» es el sacrificial ${ }^{12}$. El hablante poético se brinda a morir junto con las víctimas de la ciudad o, más aún, a ser víctima de las víctimas: «me ofrezco a ser comido / por las vacas estrujadas» (vv. 78-79). El motivo del sacrificio del poeta es el centro del poema "Ruina» (el único repetido en Revista de Occidente y Poesía española). Pero es un sacrificio inútil: ante la amenaza de la hierba voraz quedan tan solo el hablante y su «hijo» o «amor», con la única perspectiva de la muerte: «Prepara tu esqueleto; / hay que buscar de prisa, amor, de prisa, / nuestro perfil sin sueńo» (vv. 28-30). Este final se interpreta con el poema que lo sigue en Poesía española: «Ciudad sin sueño». "No es sueño la vida» (v. 20); "Hay un panorama de ojos abiertos / y amargas llagas encendidas» (vv. 60-61). La vida es un estado de vigilia, con consciencia de alienación y angustia (Craige 68); vivir así es morir, por eso en "Ruina» se asocian el esqueleto y el insomnio ${ }^{13}$.

El inútil sacrificio del poeta duplica el tratamiento de la muerte sacrificial de Jesucristo, que es un hipotexto constante en Poeta en Nueva York, como ha señalado Harris (47-54). El poema "Crucifixión» presenta el rechazo de la humanidad y pocas expectativas de resurrección ${ }^{14}$. Los ritos cristianos tampoco aportan nueva vida: el hablante de "Iglesia abandonada» ha perdido - posiblemente en la guerra- un hijo que ahora es «un pez muerto bajo la ceniza de los incensarios» (v. 11) ${ }^{15}$. Siguen otras metamorfosis por las cuales la pérdida se hace universal: «Subí a tocar las campanas, pero las frutas tenían gusanos / y las cerillas apagadas / se comían los trigos de la primavera» (vv. 13-15). En «Grito hacia Roma» se denuncia que «ya no hay quien reparta el pan y el vino» (v. 15), que «el hombre vestido de blanco

11. Sobre la tradición de la danza de la muerte, ver Ariès 118-20; Vovelle 115-19; sobre su tratamiento por Lorca, ver Menarini.

12. Sobre el sacrificio en Poeta en Nueva York, ver Saez; Craige; Nandorfy 164-208.

13. Ver Harris 43; Nandorfy 182-84. En cambio, Saez afirma que «Ruina», en el conjunto de Poeta en Nueva York, representa "the purgatorial descent to be followed by the resurrection in 'Office and Denunciation'» (115-16); sin embargo, su comentario de este último poema (121-23) habla de sarificio del poeta, no de su resurrección (y no se ve cómo podría hacerlo).

14. Marcilly (515-16) interpreta que los vv. 13-15 se refieren a la agonía de Cristo antes de la Pasión; sin embargo, la precisión «al alba» (v. 14) remite más bien a la resurrección: como si lo angustioso fuese resucitar. Ver también Nandorfy 192-95.

15. Harris (47) alude al simbolismo cristiano de estos elementos; hay que tener en cuenta además el simple dato del contraste de olores. 
[...] / ignora que Cristo puede dar agua todavía» (vv. 30, 33) y que «los maestros señalan con devoción las enormes cúpulas sahumadas; / pero debajo de las estatuas no hay amor» (vv. 40-41). Parece ser que Lorca tuvo un vivo interés en el catolicismo durante su estancia en Nueva York ${ }^{16}$; sin embargo, el poemario establece una distancia clara frente al rito y discurso religioso acerca del sentido de la muerte y la posibilidad de una nueva vida.

A ese discurso opone él sus mitos de la inocencia y de las fuerzas naturales. La inocencia es el no conocer la muerte, algo que el hablante de «1910: Intermedio" ha perdido para su desesperación: «Aquellos ojos míos de mil novecientos diez / no vieron enterrar a los muertos» (vv. 1-2); «No preguntarme nada. He visto que las cosas cuando buscan su curso encuentran su vacío» (vv. 18-19). En cambio, «El niño Stanton» guarda su inocencia en medio de la muerte y la enfermedad, y por eso es poderoso:
¡Oh mi Stanton, idiota y bello entre los pequeños animalitos, con tu madre fracturada por los herreros de las aldeas, con un hermano bajo los arcos, otro comido por los hormigueros, y el cáncer sin alambradas latiendo por las habitaciones! [...] $\mathrm{Tu}$ ignorancia es un monte de leones, Stanton. (vv. 23-27, 35)

La mención del cáncer en este poema (también en vv. 7-11) y en otros («Paisaje con dos tumbas...», vv. 4-7) pone en primer plano lo repulsivo de la muerte-todavía en 1979 escribió Sontag: «cancer is a rare and still scandalous subject for poetry» (19)-, así como los progresos de la medicalización. Pues bien, aun en estas circunstancias el niño Stanton puede "aprender celestiales palabras» que su pueblo olvida (vv. 47, 51), y quizá salvarse de la agonía de su civilización. La otra personificación de la inocencia en Poeta en Nueva York son, naturalmente, los negros de Harlem, criaturas de naturaleza animal y vegetal, a los que el poeta anima con la expectativa del inminente ocaso de la civilización urbana («El rey de Harlem», vv. 99-110).

El segundo mito restaurador lo constituyen las fuerzas naturales de tipo vegetal. Ya se ha visto el papel que tienen, por ejemplo, en «Iglesia abandonada", donde se malogra la fertilidad de la tierra en frutos y espigas. Lo vegetal tiene un papel particularmente destacado en las dos odas que cierran el ciclo de Nueva York (antes de la «huida»). El «Grito hacia Roma» termina: «Porque queremos el pan nuestro de cada día, / flor de aliso y perenne ternura desgranada, / porque queremos que se cumpla la voluntad

16. Ese interés aparece en varias cartas a su familia (García Lorca iii: 1115-16, 1122-23, 1134-35, 1157). 
de la Tierra / que da sus frutos para todos» (vv. 71-74). La «Oda a Walt Whitman" se pregunta: "¿Qué voz perfecta dirá las verdades del trigo? / ¿Quién el sueño terrible de tus anémonas manchadas?» (vv. 27-28). El trigo corresponde a Démeter y Perséfone, y las anémonas a Adonis, mitos clásicos de la fertilidad vegetal y la resurrección. Y la conclusión de este poema es una síntesis de los tres mitos que opone Lorca a la civilización y la muerte: «quiero que [...] un nińo negro anuncie a los blancos del oro / la llegada del reino de la espiga» (vv. 134-37).

Resulta evidente, en fin, que Poeta en Nueva York tiene una organización apocalíptica y cíclica que conecta con el mito de la renovación vegetal ya visto a propósito de Antonio Machado. Como se dijo entonces, Machado abandonó este mito; Lorca lo trata con una amplitud que permite reconocer sus deficiencias para el tema de la muerte. Efectivamente, el ciclo de la vegetación puede representar un final y un renacimiento colectivos, el ocaso de una civilización y el surgir de un nuevo mundo inocente y fértil, pero tiene escasa relevancia para los acontecimientos individuales. La muerte individual seguirá siendo un escándalo; en el Llanto por Ignacio Sánchez Mejias (1934) Lorca vuelve a protestar «No te conoce nadie. No» (v. 212), retomando una posición del Poema del cante jondo: «Muerto se quedó en la calle [...]. No lo conocía nadie». El ciclo natural tiene poco que decir («El Otoño vendrá con caracolas $[\ldots]$ / pero nadie querrá mirar tus ojos / porque te has muerto para siempre», Llanto, vv. 204-07). El hablante se queda sin fundamentos; no puede más que afirmarse, adversativamente, sobre su propia voluntad: «Pero yo te canto» (v. 212).

Contrastan con el Llanto las muertes individuales imaginarias del Romancero gitano (y la muerte propia imaginada en el Diván del Tamarit). Este tipo de muerte representa una liberación y una consumación. Su marco no es el mito vegetal, sino más bien la sentencia antigua -muchas veces repetida- de que conviene morirse cuanto antes ${ }^{17}$. Hay que tener en cuenta la renovación de este planteamiento en los mismos años en que escribe Lorca, con Jenseits des Lustprinzips (1920) de Freud, que pone la muerte como finalidad de la vida para todo organismo, y Sein und Zeit (1927) de Heidegger, que presenta la muerte como definitoria de la totalidad del existente humano. En particular interesa la justificación de Freud: así como todo movimiento busca restablecer un estado previo, dice, la vida toda persigue el estado previo que es la ausencia de vida, lo inorgánico. En Romancero gitano, de manera análoga, los personajes destinados a morir se asocian con

17. Por ejemplo, Heródoto, Historias, I, cap. 30-31; Sófocles, Edipo en Colono, vv. 122529; Cicerón, Tusculanas, XLVIII, 114. Ver Herzog. 
lo inorgánico y mineral, como se ha mostrado. Sea lo que fuere de estas analogías, y volviendo al marco demográfico y social contemporáneo, hay que constatar que la imaginación de la muerte individual por Lorca se aleja de las formas de morir efectivas en su entorno. Por tanto, pueden representar una evasión, pero no una respuesta a las demandas de la cambiante realidad.

\section{Conclusiones}

El análisis precedente se ha limitado a situar los textos poéticos en el contexto demográfico e ideológico que les corresponde, para identificar algunos hechos: las cuestiones que se plantean (sentido de la muerte, inmortalidad), los intentos de respuesta, el distinto tratamiento de las muertes reales y las ficticias, las individuales y colectivas. Para concluir, se trata de poner estos resultados en la perspectiva de los estudios sobre la muerte, persiguiendo los objetivos declarados al principio: entender la literatura como discurso enunciado en sociedad, y contribuir a una metodología que tenga en cuenta la especificidad de la literatura.

En primer lugar, los poemas son enunciados entre otros discursos, a veces frente a otros discursos o frente al silencio. La cuestión más llamativa señalada por Vovelle es el contraste entre el tabú social acerca de la muerte y la abundancia de sus expresiones literarias y artísticas. Ahora bien, analizada la poesía, se advierte que nace de la misma raíz, o de una de las raíces, del tabú social, según lo entiende Elias: la desorientación. Cuando la persona corriente se encuentra ante la muerte sin criterios y sin fórmulas verbales, no sabe qué decir y cae en el mutismo. La poesía, en cambio, no calla, pero no porque Machado o Lorca (o cualquier otro poeta) tenga más criterios ni un lenguaje más apropiado, sino porque se ponen en marcha para elaborar un lenguaje, hallar unos criterios y fundamentar una actitud. Sin embargo, les sucede que no llegan a posiciones determinadas (Machado), o que su visión de la muerte está demasiado lejos del proceso real individual (Lorca). Semejantes discursos, con todo su poder imaginativo y verbal, no pueden contribuir a la configuración de un sentir común que proporcione a las personas una situación clara y estable ante la muerte.

Se puede observar además el bloqueo de una determinada orientación ante la muerte: la religión. La correspondencia de Machado y de Lorca muestra su interés por el cristianismo (la de Lorca, específicamente por el catolicismo) coincidiendo con las ocasiones y temporadas en que redactan su poesía acerca de la muerte. En esta, sin embargo, lo religioso cristiano tiene un papel muy reducido (Machado), o incluso constituye un elemento 
de contraste y contradicción para el discurso propio (Lorca); en cambio, se prueba a fundar las actitudes del hablante poético en el pensamiento mítico o el poder autónomo del espíritu humano. Hay aquí cuestiones que van más allá de la problemática de la muerte. Se trata, por un lado, de la secularización, una secularización que posiblemente avanza más rápido en el nivel de la sociedad que en el de los individuos, por lo que estos censuran sus propios enunciados públicos. Por otro lado, se trata de que la poesía anda en busca de su autonomía y su propia autoridad; no se contenta con ser el revestimiento de poderes e ideas generados en otra parte (como se veía en Garcilaso de la Vega), sino que quiere constituirse de propio derecho en fuente de verdad. Esto es cosa conocida; lo que pueden aportar investigaciones como esta sobre la muerte y la poesía es el análisis de las estrategias concretas que se emplean en un área determinada.

Desde este punto se puede proponer una orientación metodológica a los estudios sobre la muerte. La poesía no puede tomarse ni como mero contraste con las actitudes generalizadas (abundancia frente a tabú) ni como mera expresión de las representaciones colectivas. La poesía ciertamente crece de la misma raíz que el resto de las manifestaciones de la sociedad, pero se distingue por su capacidad de articular las preguntas vigentes en su momento histórico, de examinar y someter a prueba las respuestas, y quizá por la clarividencia para encontrarlas insuficientes y descartarlas. Pues otro aspecto de la búsqueda de la autonomía por la poesía es que no pretende alcanzarla a costa de la verdad. Esta condición proporciona al observador un criterio para discernir los límites de las propuestas que circulan en la sociedad, lo que es cuestionable en ellas, sus incoherencias e insuficiencias. En este caso, el recurso a los mitos hace que resulte más fácil hablar del final colectivo (ocaso del mundo, de la civilización occidental) que del individual (la muerte de cada uno). Las representaciones colectivas no se ajustan perfectamente a las necesidades, queda un residuo de insatisfacción, y en él se encuentra la posibilidad del desarrollo y de conflicto; un conflicto que para el caso de la muerte es sobre todo interno a cada individuo y se manifiesta globalmente como enmudecimiento y desconsuelo. 


\section{Obras citadas}

Albaladejo Tomás, Semántica de la narración: la ficción realista, Madrid, Taurus, 1992.

Alonso Dámaso, «Muerte y trasmuerte en la poesía de Antonio Machado», Revista de Occidente, 5-6, 1976, 11-24.

Alvar Manuel, «Introducción», en Antonio Machado, Los complementarios, ed. Manuel Alvar, Madrid, Cátedra, 1980, 9-69.

Anderson Andrew A., "The Evolution of García Lorca's Poetic Projects 1929-1936 and the Textual Status of Poeta en Nueva York», Bulletin of Hispanic Studies, 60, 1983, 221-46.

- Lorca's Late Poetry: A Critical Study, Liverpool, Cairns, 1990.

Ariès Philippe, L'Homme devant la mort, 2 vols., Paris, Seuil, 1977.

Bakhtin M. M., The Dialogic Imagination: Four Essays, ed. Michael Holquist, Austin, University of Texas Press, 1981.

Cerezo Galán Pedro, Palabra en el tiempo: poesía y filosofía en Antonio Machado, Madrid, Gredos, 1975.

Ciplijauskaité Biruté, "Ser y estar en la palabra: Machado, Heidegger y la deconstrucción", en John P. Gabriele (dir.), Divergencias y unidad: perspectivas sobre la Generación del 98 y Antonio Machado, Madrid, Orígenes, 1990, 227-44.

Cobos Pablo de A., Sobre la muerte en Antonio Machado, Madrid, Ínsula, 1972.

Correa Gustavo, La poesía mítica de Federico García Lorca, 2. a ed., Madrid, Gredos, 1975.

- «Una "lira inmensa”: el ritmo de la muerte y de la resurrección en la poesía de Antonio Machado", en Estudios sobre Antonio Machado, Barcelona, Ariel, 1977, 121-162.

Craige Betty Jean, Lorca's Poet in New York: The Fall into Consciousness, Lexington, UP of Kentucky, 1977.

Dennis Nigel, Vida y milagros de un manuscrito de Lorca: en pos de "Poeta en Nueva York", Santander, Sociedad Menéndez Pelayo, 2000.

Dopico Fausto, y Reher David-Sven, El declive de la mortalidad en España, 18601939, Barcelona, Asociación de Demografía Histórica, 1998.

Eagleton Terry, The Ideology of the Aesthetic, Oxford, Blackwell, 1990.

- Después de la Teoría, Barcelona, Debate, 2005.

Egginton William, «Facing the Defacement of Death: Heidegger, Deleuze, and García Lorca", en Convergencias Hispánicas: Selected Proceedings and Other Essays on Spanish and Latin American Literature, Film, and Linguistics, Newark (DE), Cuesta, 103-117.

Elias Norbert, La soledad de los moribundos, México, FCE, 1987. 
Erasmo de Rotterdam Desiderio, Preparación y aparejo para bien morir, trad. Bernardo Pérez de Chinchón, ed. Joaquín Parellada, Madrid, Fundación Universitaria Española - Universidad Pontificia de Salamanca, 2000.

Feal Deibe Carlos, Eros y Lorca, Barcelona, Edhasa, 1973.

Fernández Alonso María del Rosario, Una visión de la muerte en la lírica española: la muerte como amada, Madrid, Gredos, 1971.

Frye Northrop, Anatomy of Criticism: Four Essays, Princeton, Princeton UP, 1957.

García Lorca Federico, Obras completas, Miguel García-Posada (ed.), 4 vols., Barcelona, Galaxia Gutenberg, 1996-1997.

Garcilaso de la Vega, Obra poética y textos en prosa, Bienvenido Morros (ed.), Barcelona, Crítica, 1995.

Gibson Ian, Federico García Lorca, I: de Fuente Vaqueros a Nueva York, Barcelona, Grijalbo, 1985.

Griffin Roger, Modernism and Fascism: The Sense of a Beginning under Mussolini and Hitler, Basingstoke, Palgrave Macmillan, 2007.

Guillén Claudio, «Estilística del silencio», Revista Hispánica Moderna, 1957, 23, 260-91.

Güntert Georges, «Antonio Machado: A José María Palacio», en Cien años de poesía: 72 poemas españoles del siglo XX: Estructuras poéticas y pautas críticas, Bern, Peter Lang, 2001, 59-70.

Harris Derek, Federico García Lorca: Poeta en Nueva York, London, Grant \& Cutler / Tamesis, 1978.

Herrera Fernando de, Anotaciones a la poesía de Garcilaso, Inoria Pepe y José María Reyes (eds.), Madrid, Cátedra, 2001.

Herrero Javier, «The Spider-Moon: The Origin of Lorca's Lunar Myth», en Dian Fox, Harry Sieber, Robert Ter Horst (eds.), Studies in honor of Bruce W. Wardropper, Newark, Juan de la Cuesta, 1989, 147-62.

- "Negros maniquís de sastre": Death and Resurrection in Lorca's "Martirio de Santa Olalla" ", en Ann Mackenzie (ed.), Hispanic Studies in Honour of Geoffrey Ribbans, Liverpool, Liverpool UP, 1992, 259-65.

Herzog, Reinhart, "Vom Aufhören», en Karlheiz Stierle y Rainer Warning (eds.), Das Ende: Figuren einer Denkform, München, Fink, "Poetik und Hermeneutik» 16, 1996, 283-329.

Iglesias Feijoo Luis, «Lectura de la Égloga I», en Víctor García de la Concha (ed.), Garcilaso: IV Academia Literaria Renacentista, Salamanca, Universidad, 1986, 61-82.

Kermode Frank, The Sense of an Ending: Studies in the Theory of Fiction, Oxford, Oxford UP, 1967.

López Castellón Enrique, Federico García Lorca: el poeta ante la muerte, 2. ${ }^{\text {a }}$ ed., Madrid, Busma, 1984. 
Loughran David K., Federico Garcia Lorca: The Poetry of Limits, London, Tamesis, 1978.

Machado Antonio, Poesía y prosa, Oreste Macrí (ed.), 4 vols., Madrid, EspasaCalpe, 1989.

Marcilly Charles, "Notes pour l'étude de la pensée religieuse de F. García Lorca: "Crucifixión" ", en Mélanges offerts à Marcel Bataillon, Bulletin Hispanique, 1962, 64 bis, 507-25.

Menarini, Piero, "La danza de la muerte en Poeta en Nueva York», Boletín de la Fundación Federico García Lorca, febrero 1992, 10-11, 147-163.

Nandorfy Martha J., The Poetics of Apocalypse: Federico Garcia Lorca's Poet in New York, Lewisburg, Bucknell UP, 2003.

Picard Michel, La Littérature et la mort, Paris, PUF, 1995.

Poust Alice J., «Federico García Lorca’s Andalusia in light of Oswald Spengler's Theory of Magian Cultures», en Manuel Delgado Morales, Alice J. Poust (eds.), Lorca, Buñuel, Dali: Art and Theory, Lewisburg: Bucknell UP, 2001, 175-90.

Reinholtz Eric, «Morphology of the Duende: The Theory and Praxis of Death in the Poetry of Federico García Lorca», en Patricia Rae (ed.), Modernism and Mourning, Lewisburg, Bucknell UP, 2007, 136-153.

Ribbans Geoffrey, "Machado's 'Ciclo de Leonor'», en D. T. Gies (ed.), Negotiating Past and Present: Studies in Spanish Literature for Javier Herrero, Charlottesville, Rookwood, 1997, 76-91.

Saez Richard, "The ritual sacrifice in Lorca’s Poeta en Nueva York», en Manuel Durán (ed.), Lorca: A Collection of Critical Essays, Englewood Cliffs (NJ), Prentice-Hall, 1962, 108-28.

Salinas Pedro, Ensayos de literatura hispánica: del "Cantar de mio Cid» a García Lorca, Madrid, Aguilar, 1958.

Sánchez Barbudo Antonio, Estudios sobre Unamuno y Machado, Madrid, Guadarrama, 1959.

- Los poemas de Antonio Machado: los temas, el sentimiento y la expresión, Barcelona, Lumen, 1969.

Sontag Susan, Illness as Metaphor, New York, Vintage Books, 1979.

Terry Arthur, Antonio Machado: Campos de Castilla, London, Grant \& Cutler I Tamesis, 1973.

Tynianov J. y R. Jakobson, «Les problèmes des études littéraires et linguistiques» [1928], en Tzvetan Todorov (ed. y trad.), Théorie de la littérature: textes des formalistes russes reunis, Paris, Seuil, 1965, 138-40.

Urrea Beatriz, "Silencio, amor y muerte: el homosexual y la mujer en la obra de García Lorca", Bulletin of Hispanic Studies, 1997, 74, 37-58.

Vovelle Michel, La Mort et l'Occident: de 1300 à nos jours, Paris, Gallimard, 1983. 
